\title{
Postural response of intraocular pressure in chronic open-angle glaucoma following trabeculectomy
}

\author{
J PARSLEY, ${ }^{*} \mathrm{R}$ G POWELL, S J KEIGHTLEY, ANd A R ELKINGTON \\ From the Department of Surgery, Southampton University, and Southampton Eye Hospital
}

\begin{abstract}
SUMmaRY Forty-six eyes with chronic open-angle glaucoma (COAG) and 24 eyes which had previously undergone trabeculectomy for COAG were studied and the postural reponse of the intraocular pressure compared with that of 70 normal eyes. In all three groups the greatest rise in intraocular pressure (IOP) occurred when the subject changed from the sitting to the lying position. In the control group this was never more than $2 \mathrm{mmHg}$ in any subject. The rise was greater than $2 \mathrm{mmHg}$ in $93 \%$ of the patients suffering from COAG who were treated medically and in $100 \%$ of the eyes of those on which trabeculectomy had been performed. The well recognised abnormal postural response of intraocular pressure in COAG appears both to be retained and to be unaffected in those eyes which have undergone trabeculectomy.
\end{abstract}

An abnormal postural response of the intraocular pressure (IOP) is well known in patients with chronic open-angle glaucoma (COAG) ${ }^{1.3}$ and associated disorders such as retinal vein occlusion ${ }^{45}$ and ocular hypertension. ${ }^{6}$ An abnormal postural response of IOP in eyes which had suffered a traumatic hyphaema has also been described. ${ }^{7}$

Trabeculectomy is a well established method of surgical treatment of COAG. ${ }^{*}$ We studied the postural intraocular pressure response in patients with COAG to determine whether or not an abnormal response was retained after this operation.

\section{Materials and methods}

Thirty-five patients attending for outpatient treatment of chronic open-angle glaucoma at Southampton Eye Hospital were examined. Twenty of these patients had received medical therapy only for control of their glaucoma. They had a mean age of $69 \cdot 8$ years (range 52 to 85 years), there being 11 males and nine females. The other 15 patients (seven males and eight females) had undergone a trabeculectomy operation within six years of the current examination, though no account was taken of the time elapsing between surgery and the examination. Nine of these 15 patients had undergone bilateral trabeculectomy and had a mean age of 70.6 years (range 52 to 81 years). The other six patients had undergone * Work undertaken during fourth year medical student elective. Correspondence to Mr S J Keightley, FRCS, Southampton Eye Hospital, Wilton Avenue, Southampton SO9 4XW. unilateral trabeculectomy and had a mean age of 73.0 years (range 58 to 85 years). The criteria for the diagnosis of COAG to be made in all patients included all the following features: untreated IOP greater than $21 \mathrm{mmHg}$ by Goldman applanation tonometry, glaucomatous cupping of the optic disc, characteristic glaucomatous visual field defects, and gonioscopically open anterior chamber angles.

A series of 35 control patients (70 eyes) was also examined. Sixteen of these patients were male, 19 were female. The mean age of the patients was 72.6 years (range 65 to 87 years). These patients were being followed up in the outpatient department for the progression of early cataracts. All had routine applanation tonometry and examination of the optic discs to exclude COAG.

No account was taken of the use of either topical or systemic drug therapy in any case.

All intraocular pressure measurements were taken as an average of two 10-second recordings with an Alcon Applanation Pneumotonograph which had been recently calibrated. The required posture was assumed for 10 minutes before each pressure measurement, and recordings were made in the following postures consecutively: standing, sitting, and lying. The right eye was always examined first.

\section{Results}

The mean intraocular pressures of the four groups in the three positions are shown in Table 1 and are illustrated in Fig. 1. 
Table 1 Mean (standard error) intraocular pressures in $\mathrm{mmHg}$

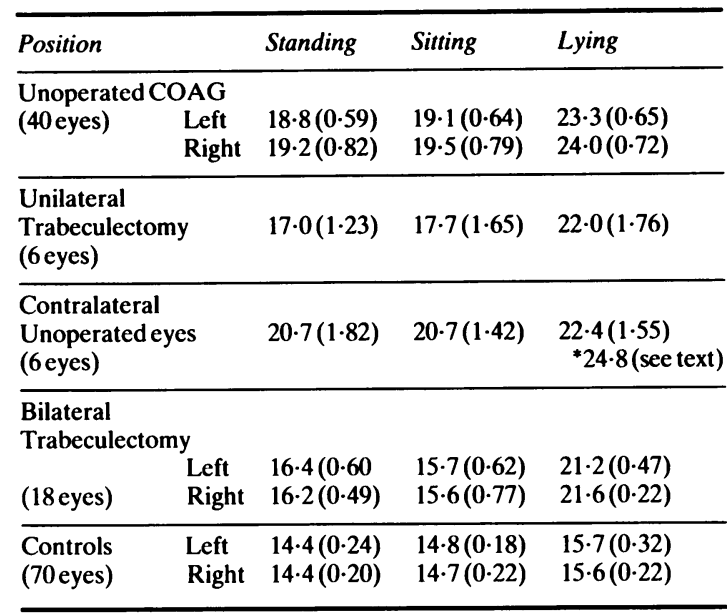

The greatest rise in IOP occurred on changing from the sitting to the lying position in all groups. No eye in the control group showed a rise of more than 2 $\mathrm{mmHg}$. However, all but two (separate patients) of

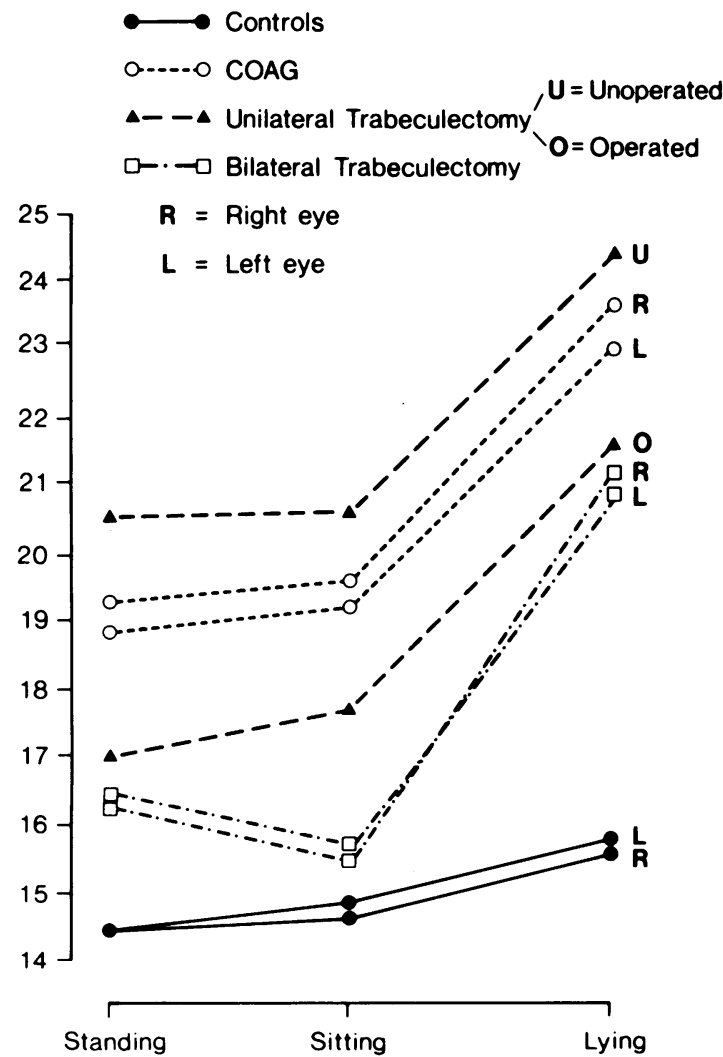

Fig. 1 Mean intraocular pressures of the four groups of patients in different postures. the 40 unoperated glaucomatous eyes had a rise in IOP greater than $2 \mathrm{mmHg}$. All 18 eyes in the bilateral trabeculectomy group and all six in the unilateral trabeculectomy group had a rise greater than 2 $\mathrm{mmHg}$ on changing from the sitting to the lying position. Five out of the six contralateral unoperated eyes similarly had a rise greater than $2 \mathrm{mmHg}$. However, the sixth unoperated eye had a fall of $7 \cdot 5$ $\mathrm{mmHg}$, the IOP being recorded as $17.5 \mathrm{mmHg}$ in the lying position. This IOP value was very low (standardised value 3.48) and appears to be erroneous. Analysis confirms that this response was significantly different from the overall pattern $(p<0.001)$. A reanalysis, treating this value as missing, produced a much more coherent pattern of results and is to be preferred. ${ }^{9}$ The asterisk * in Table 1 denotes the mean IOP value in the lying position when this very low value is considered missing in the unoperated group of eyes.

There was no significant difference in postural response of IOP by age or sex (observed $\mathrm{F}_{66}^{3}=0 \cdot 61$, $\mathrm{p}>0.05$ ), and the difference between the IOPs in the standing and sitting positions was also not significant (observed $F_{132}^{1}=0.04, p>0.05$ ).

However, there was a significant difference between the mean standing/sitting position and the lying pressure in all patient groups (observed $F_{132}=377 \cdot 1, p>0.01$ ). There was also a significant difference in the amount of pressure change between groups (observed $\mathrm{F}_{132}{ }^{3}=4.39, \mathrm{p}<0.01$ ). The rank order of these pressure rises was bilateral trabeculectomy $5.46 \mathrm{mmHg}$, medically treated glaucoma 4.43 $\mathrm{mmHg}$, unilateral trabeculectomy $3.31 \mathrm{mmHg}$, and controls $1.08 \mathrm{mmHg}$.

\section{Discussion}

Anderson and Grant ${ }^{2}$ provided data on the effect of different methods of treating COAG on the postural intraocular pressure response. Their results showed a mean IOP rise of $2.83 \mathrm{mmHg}$ in eyes treated by surgery on changing from the sitting to the lying position. Groups of eyes receiving various medical treatments had a mean IOP rise of less than half this value. These results contrast strongly with the present study, in which eyes suffering from COAG treated medically and surgically have similar mean IOP rises of $4.02 \mathrm{mmHg}$ and $5.49 \mathrm{mmHg}$ respectively on changing from the sitting to the lying position. However, it is important to note that Anderson and Grant examined only six eyes which had undergone trabeculectomy, as compared with 159 eyes which were receiving medical therapy, and hence comparisons between the two studies must be limited.

These results confirm the value of IOP measurements in the lying position in patients with COAG, 
because the intraocular pressure may be dangerously high on lying down as a consequence of the abnormal postural response. Even in the trabeculectomy groups the mean IOP was above $21 \mathrm{mmHg}$ in the lying position $(21.39$ and $22.0 \mathrm{mmHg}$ for bilateral and unilateral trabeculectomy respectively). This may account in part for the progression of the disease even when the IOP as recorded by the Goldmann applanation tonometer appears to be within the normal range.

\section{References}

1 Hetland-Eriksen J. On tonometry. The pressure of glaucomatous eyes measured in the sitting and lying positions by means of the Goldmann applanation tonometer. Acta Ophthalmol (KGh) 1966; 44: 515-21.

2 Anderson DR, Grant WM. The influence of position on intraocular pressure. Invest Ophthalmol Vis Sci 1973; 12: 204-12.
3 Kriegelstein GK, Langham ME. Influence of body position on the intraocular pressure of normal and glaucomatous eyes. Ophthalmologica 1975; 171: 132-45.

4 Williams BI, Peart WS. Effect on posture on the intraocular pressure of patients with retinal vein obstruction. $\mathrm{Br} J$ Ophthalmol 1978; 62: 688-93.

5 Williams BI, Peart WS. Retinal vein obstruction and intraocular pressure; abnormal postural response independent of facility of outflow. Br J Ophthalmol 1979; 63: 805-7.

6 Leonard TJK, Kerr-Muir MG, Kirkby GR, Hitchings RA. Ocular hypertension and posture. BrJ Ophthalmol 1983; 67: 362-6.

7 Anid G, Powell RG, Elkington AR. Postural response of intraocular pressure following traumatic hyphaema. $\mathrm{Br} J$ Ophthalmol 1985; 69: 576-9.

8 Watson PG, Barnett F. Effectiveness of trabeculectomy in glaucoma. Am J Ophthalmol 1975; 79: 831-45.

9 Snedecor GW, Cochran WG. Statistical methods. 7th ed. Iowa University State Press, 1980: 281.

Accepted for publication 15 August 1986. 